\title{
La producción artesanal dentro del urbanismo de las civitates del Ebro Medio
}

\author{
Craft production in the urban planning \\ of the civitates of the Middle Ebro
}

Adrián Calonge Miranda

Investigador Agregado.

Instituto de Estudios Riojanos

E-mail: adricalon24@gmail.com

Orcid ID: https://orcid.org/0000-000 I-5701-7450
RECIBIDO: 29 DE NOVIEMBRE DE 2021 ACEPTADO: 8 DE ENERO DE 2022
Resumen: El valle medio del Ebro se configuró en época romana como una zona dinámica que tenía unas conexiones terrestres y fluviales. Se desarrolló un conglomerado de ciudades donde predominaban las de pequeño tamaño junto con casos como los de Pompaelo (Pamplona, Navarra) y Caesaraugusta (Zaragoza, Aragón) que contaban con un tamaño mayor. Gracias al avance de la investigación en las entidades urbanas, se puede ubicar el lugar donde se levantaron las zonas productivas y los distritos artesanales, integrados o no en su urbanismo. El objetivo principal es analizar estas demarcaciones productivas en su relación con el resto de la ciudad y de las infraestructuras de comunicación, así como su desarrollo.

Palabras Clave: Civitates, centros artesanales, Ebro Medio, urbanismo.

\begin{abstract}
The middle valley of the Ebro was configured in Roman times as a dynamic area that had land and river connections. A conglomerate of cities was developed where the small ones predominated, together with cases such as those of Pompaelo (Pamplona, Navarra) and Caesaraugusta (Zaragoza, Aragón) that had a larger size. Thanks to the progress of research in urban entities, it is possible to locate the place where the productive zones and artisanal districts were built, integrated or not in their urban planning. The main objective is to analyze these productive demarcations in their relationship with the rest of the city and the communication infrastructures as well as their development.
\end{abstract}

Keywords: Civitates, craft centers, Middle Ebro, urbanism.

CAUN 30 (2022): [1-28] 135-162

ISSN: 1133-1542. ISSN-e: 2387-1814

DOI: https://doi.org/10.15581/012.30.006 


\section{A MODO DE INTRODUCCIÓN}

E

L entramado urbano era un crisol de situaciones donde se establecían barrios o, al menos, áreas específicas que incluían zonas de representación, de viviendas, edificios de intercambio comercial o estancias de carácter productivo. Cada una de ellas tenían su lugar dentro de la ciudad siendo para las primeras el más privilegiado, para las segundas se reservaba la mayor parte de la superficie, las terceras gozaban de un emplazamiento cercano a las vías de salida y las cuartas podían tener una gran variedad de ubicaciones.

La zona de estudio propuesta comprende los enclaves urbanos que más información han proporcionado en el valle medio del Ebro en los actuales territorios de La Rioja y Navarra (Figura 1). Se trata de un entorno con una gran riqueza agropecuaria gracias a los diferentes valles de la densa red hidrográfica a lo que hay añadir recursos mineros en las sierras cercanas el Sistema Ibérico o las canteras de arenisca en la Navarra Media. Las investigaciones llevadas a cabo en el Ebro Medio posibilitan poder analizar la ubicación de los distritos artesanales dentro del urbanismo de las ciudades y su relación con las vías de comunicación tanto terrestres como fluviales. En este caso la calzada que utilizaba el valle del Hiberus para enlazar el Levante con la zona del noroeste (Itin. Ant. 387.4-395.4 y 448.2-452-5), así como las vías trasversales norte-sur que conectaban el cauce principal con el nacimiento del Duero a través de los valles de los ríos Najerilla, Iregua, Cidacos y Alhama-Linares por el sur y con los Pirineos y el mar Cantábrico por el norte gracias a las cuencas del Ega, el Arga, el Aragón o el Zidacos.

Las diferentes producciones artesanales en estos distritos eran diversos e iban desde el almacenamiento de alimentos hasta zonas de transformación en alfares, crisoles metalúrgicos o industrias textiles con un volumen que miraba hacia la ciudad y a un mercado más regional. Además, compartían red comercial con los enclaves rurales que se desarrollaron en el ámbito suburbano y cuya materia prima también debía abastecer a estas industrias. Por todo ello, se va a analizar su situación dentro de la ciudad continuando con la diversidad de manufacturas y se terminará abordando su evolución a lo largo de los siglos de dominación romana. 


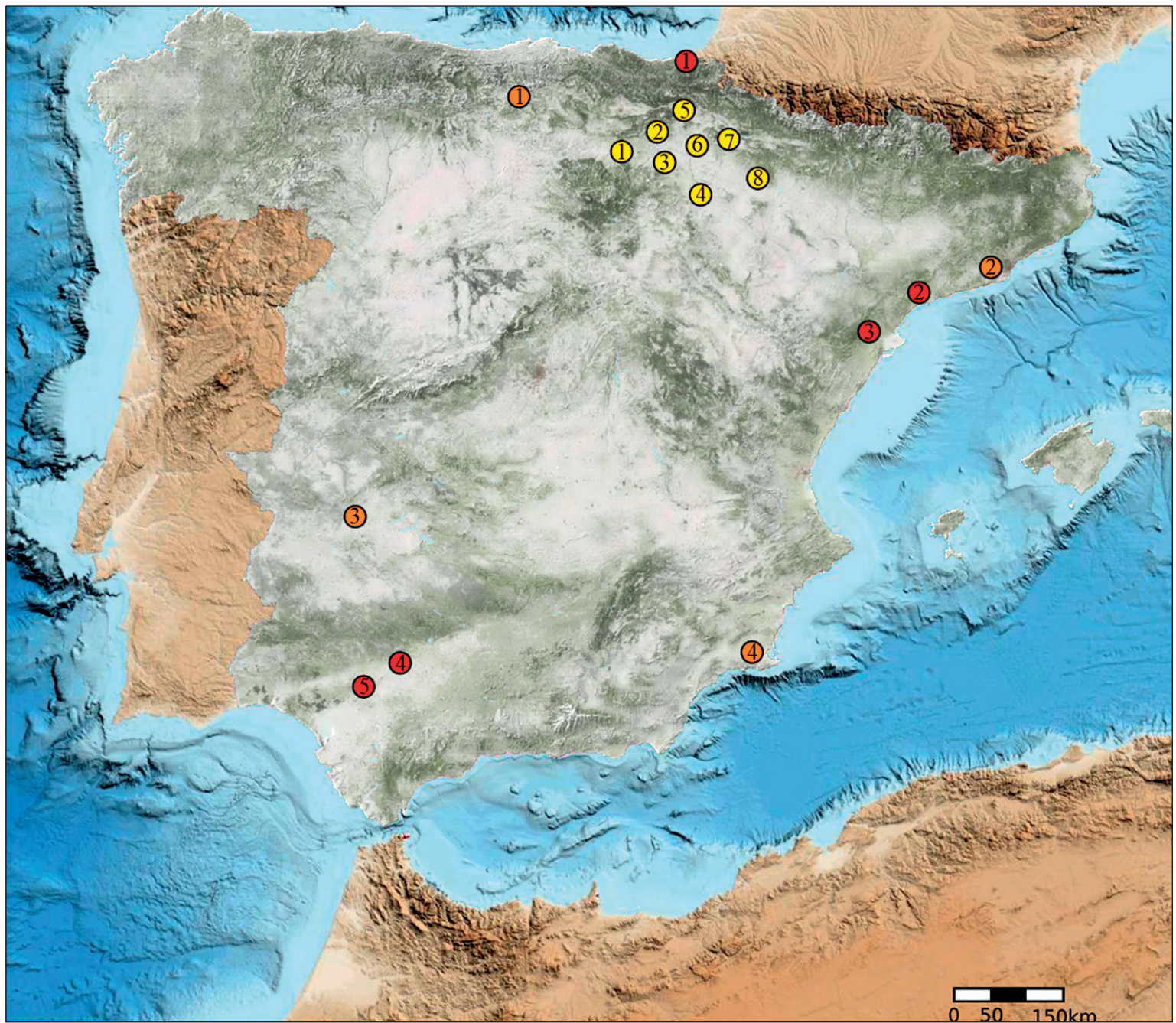

Figura 1

Ciudades estudiadas y mencionadas dentro de la zona de estudio propuesta

(Elaboración propia/Visor Iberpix/IGN, consultada el 29/01/2022).

Del Ebro Medio (amarillo):

1. Vareia (Varea, Logroño, La Rioja); 2. Andelos (Mendigorría, Navarra);

3. Calagurris Iulia (Calahorra, La Rioja); 4. Graccurris (Alfaro, La Rioja);

5. Pompaelo (Pamplona, Navarra); 6. Cara (Santacara, Navarra); 7. Santa Criz (Eslava, Navarra) y 8. Los Bañales (Uncastillo, Aragón).

Comparativa de casos (naranja):

1. Iuliobriga (Retortillo, Cantabria); 2. Barcino (Barcelona, Cataluña);

3. Emerita Augusta (Mérida, Extremadura) y 4. Cartago Nova (Cartagena, Murcia).

Ciudades mencionadas (rojo):

1. Oiasso (Irún, País Vasco); 2. Tarraco (Tarragona, Cataluña); 3. Dertosa (Tortosa, Cataluña);

4. Carmo (Carmona, Andalucía) y 5. Hispalis (Sevilla, Andalucía). 


\section{LA PRODUCCIÓN ARTESANAL: UNA MIRADA URBANÍSTICA}

\subsection{Localización en el interior de la ciudad}

Dentro de los entornos urbanos de la zona media del Ebro, destaca la agrupación de varios talleres artesanales en un determinado lugar de la ciudad. Se trataba de zonas funcionalmente mixtas donde estaban las estancias productivas, las de venta y también las de habitación. Se asientan en espacios ordenados y perfectamente integrados en el urbanismo de la ciudad junto a las vías de acceso.

\subsubsection{Andelos (Mendigorría, Navarra)}

Uno de los casos más claros se encuentras en el municipium flavio de Andelos. Se han logrado exhumar restos de una ciudad compartimentada en insulae alargadas de $30 \times 75 \mathrm{~m}$ y adaptada a la orografía mediante la ejecución de plataformas bien niveladas. En la inferior, se encontró un entramado viario que combinaba un cardus porticado con el decumanus por donde se había ejecutado el último tramo del acueducto (Mezquíriz, 1996: 442-444). Es en este sector se han localizado una serie de talleres, almacenes y viviendas que estaban situados junto a la salida occidental de la ciudad y se abrían a diferentes calles (Mezquíriz, 2009a: 74) (Figura 2.). La necesidad de agua para este barrio artesanal hizo que en el siglo II se ejecutase un segundo ramal de la canalización de abastecimiento hacia el sur alzado sobre pilares siguiendo probablemente un cardus (Mezquíriz y Unzu, 1988: 245-250).

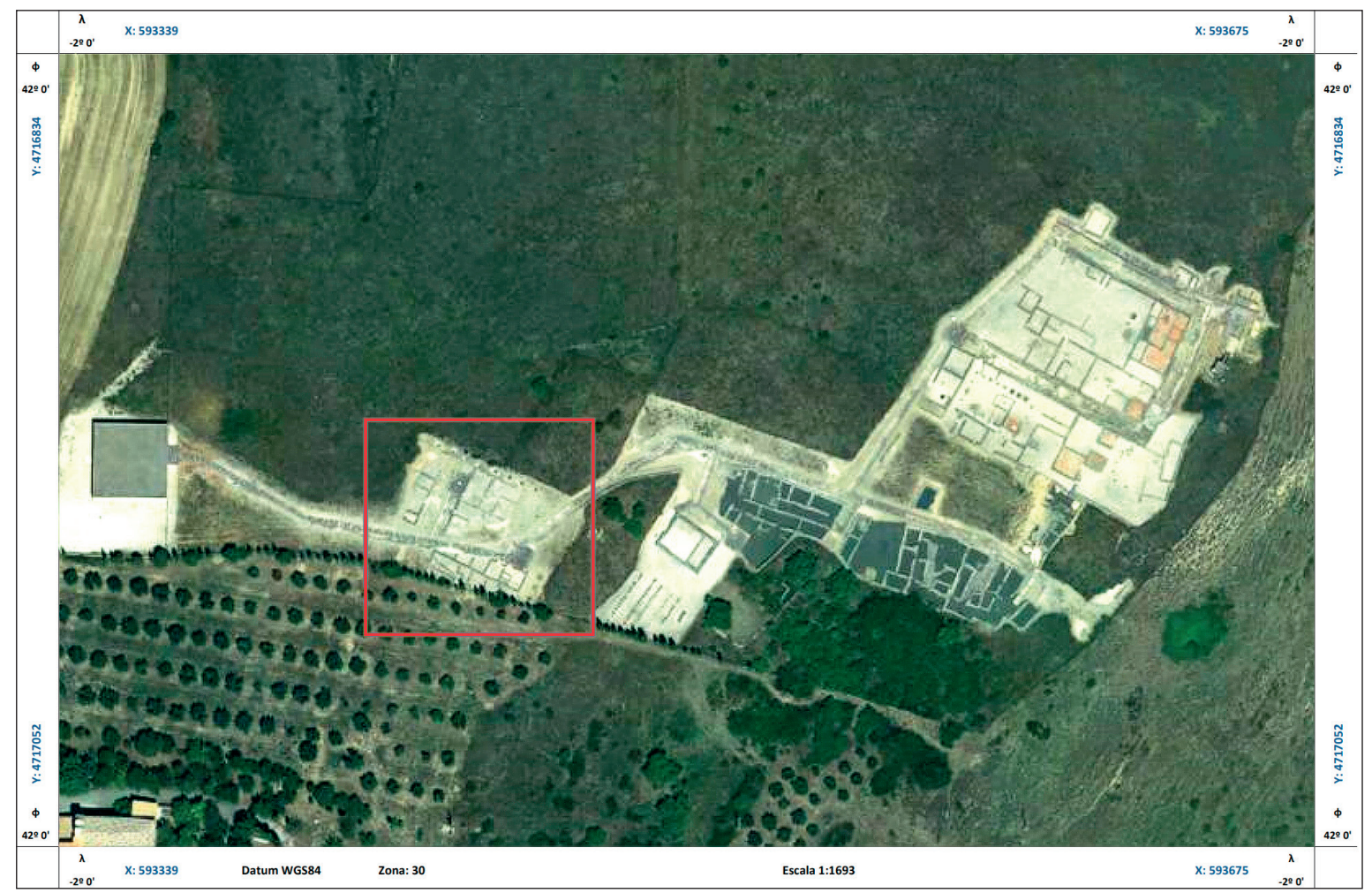

Figura 2

Barrio artesanal de Andelos (Mendigorría, Navarra)

(Visor Iberpix/IGN, consultado el 11/01/2022) 


\subsubsection{Santa Criz de Eslava (Navarra)}

En el término de Santa Criz de Eslava, se está investigando una civitas cuyo nombre aún es esquivo pero que ha proporcionado dos interesantes conjuntos: parte del foro y una de las necrópolis de la ciudad (Armendáriz y Sáenz de Albéniz, 2016: 245-285). De entre el primero destaca la existencia de un criptopórtico al que se adosaba al sur una construcción de planta rectangular que ha sido interpretada como un almacén (Cebrián et al., 2020: 236-238).

En planta presenta 32,15 m de longitud y 15,70 de ancho compartimentado en 8 naves de 11,25 × 3,50 $\mathrm{m}$ con acceso desde el sur gracias a un corredor de 2,70 $\mathrm{m}$ de anchura (Figura 3). Los muros se ejecutaron en opus vitattum sin argamasa (Armendáriz y Sáenz de Albéniz, 2016: 263; Cebrián Fernández et al., 2020: 222-223) y es destacable que se descubriera en el interior de las 8 naves pequeñas estructuras cuadrangulares de 0,73 m de lado. Estaban adosados a la cara interna y se han interpretado como parte de los posibles soportes para un tabulatum lo que facilitaría la conservación del cereal (Armendáriz y Sáez de Albéniz, 2016: 263-264). Funcionalmente también pudo constituir un espacio de almacenaje y de venta.

El conjunto foral fue construido a lo largo del siglo I, fecha en la que también se levantó el horrecum de Santa Criz que no hay que olvidar que servía de punto de apoyo para gran parte de la zona de representación de la ciudad. Se han planteado dos hipótesis sobre la amortización del espacio de almacenamiento: su conversión en una plaza

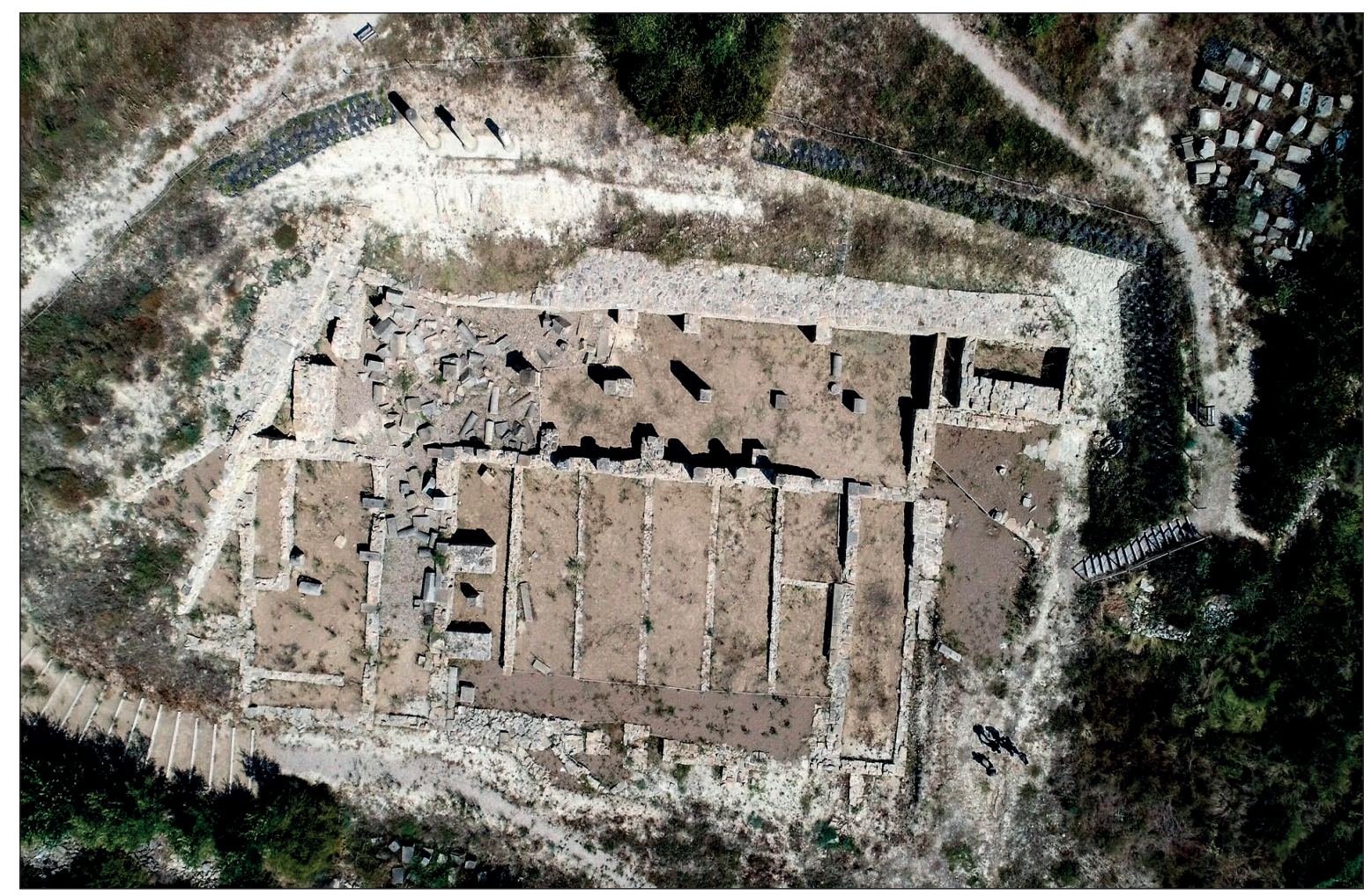

Figura 3

Foro y el almacén de Santa Criz

(Fotografía cenital de José Luis Espuelas cortesía de Luis Romero Novella) 
pública con pórtico en forma de U abriéndose hacia el sur (Armendáriz Aznar y Sáez de Albeniz, 2016: 250-251) y su derribo dentro de un proceso de renovación de la zona sur del conjunto (Cebrián et al., 2020: 235-236), ambas entre finales del siglo I y principios del II mientras que el foro terminaría colapsando durante la tercera centuria.

\subsubsection{Vareia (Barrio de Varea, Logroño, La Rioja) (Figura 4)}

Ofrece una variada situación de sus ámbitos artesanales a lo largo de sus seis siglos de historia. Entre finales de la primera centuria y principios de la siguiente, la ciudad creció hacia el sur superando la calzada De Italia in Hispanias cuyo trazado se oculta bajo la actual calle Calahorra (Itin.Ant., 393.2) tal y cómo se ha podido constatar durante las excavaciones del PERI 48 Carrocerías Ugarte. Este nuevo suburbio fue planificado mediante una serie de insulae y compartía la misma orientación que el entramado viario del resto del núcleo civil.

Como en el caso de Andelos, se han localizado estancias domésticas que incluían algunos elementos suntuarios como atrios pavimentados, zonas calefactadas o paredes estucadas junto a talleres de índole textil, metalúrgico o del tratamiento de cuero. Difiere, sin embargo, en la calidad de los materiales de construcción de las estructuras, más homogéneo en el caso navarro. Pese a la existencia de un cierto nivel de lujo en los hogares, la mayor parte de las estancias tiene una cimentación de piedra sobre la que se hicieron las paredes de tapial (Tudanca y López de Calle, 2018: 51-53). Son construcciones más humildes que las constadas en otras zonas del yacimiento.

Justo al norte, en la actual calle Artesanos, se ubicó una de las principales entradas a la ciudad con un amplio cardus porticado que daba una plaza de la que partía otra calle con la misma orientación que articulaba un sector artesanal y comercial. Durante el bajoimperio, el primer tramo de la calle conservaba el sistema porticado sustituyendo las columnas de piedra por pilares de madera mientras que se constata una ocupación del dominio público teniendo que habilitar un antiguo comercio para que pudiera continuar en uso. Entorno a esta configuración urbanística se distribuyeron varios talleres metalúrgicos, de manipulado textil o vinculado con la industria alimenticia junto a tabernae de venta comercial. Se presupone una configuración similar en época altoimperial aunque con los cardines completamente operativos y despejados de ocupaciones privadas (Martínez y Gallego, 1994: 315-318).

La ciudad observa una monumentalización de sus ambientes domésticos durante los siglos bajoimperiales pero con la peculiaridad de usar como modelo la planta de las villae rurales. De esta manera, se construyen zonas productivas junto a las estancias destinadas a vivienda. Este hecho quedó constatado bajo el actual colegio Varia donde se localizó un amplio cardus que separada dos domi: la oriental contaba con un 
horreum de almacenamiento $\mathrm{y}_{\mathrm{y}}$ la oriental con una planta de procesamiento de aceite donde se conservada in situ el lacus torcularis. El almacén es una gran sala que contaba con 9 grandes sillares cuadrangulares ordenadas de tres de fondo que servían de apoyo para los pilares de madera que sustentaban una techumbre a dos aguas. Entre la cultura material destacaba la gran cantidad de molinos por lo que fue interpretado como un lugar de depósito de grano. (Espinosa et al., 1994: 329-332).

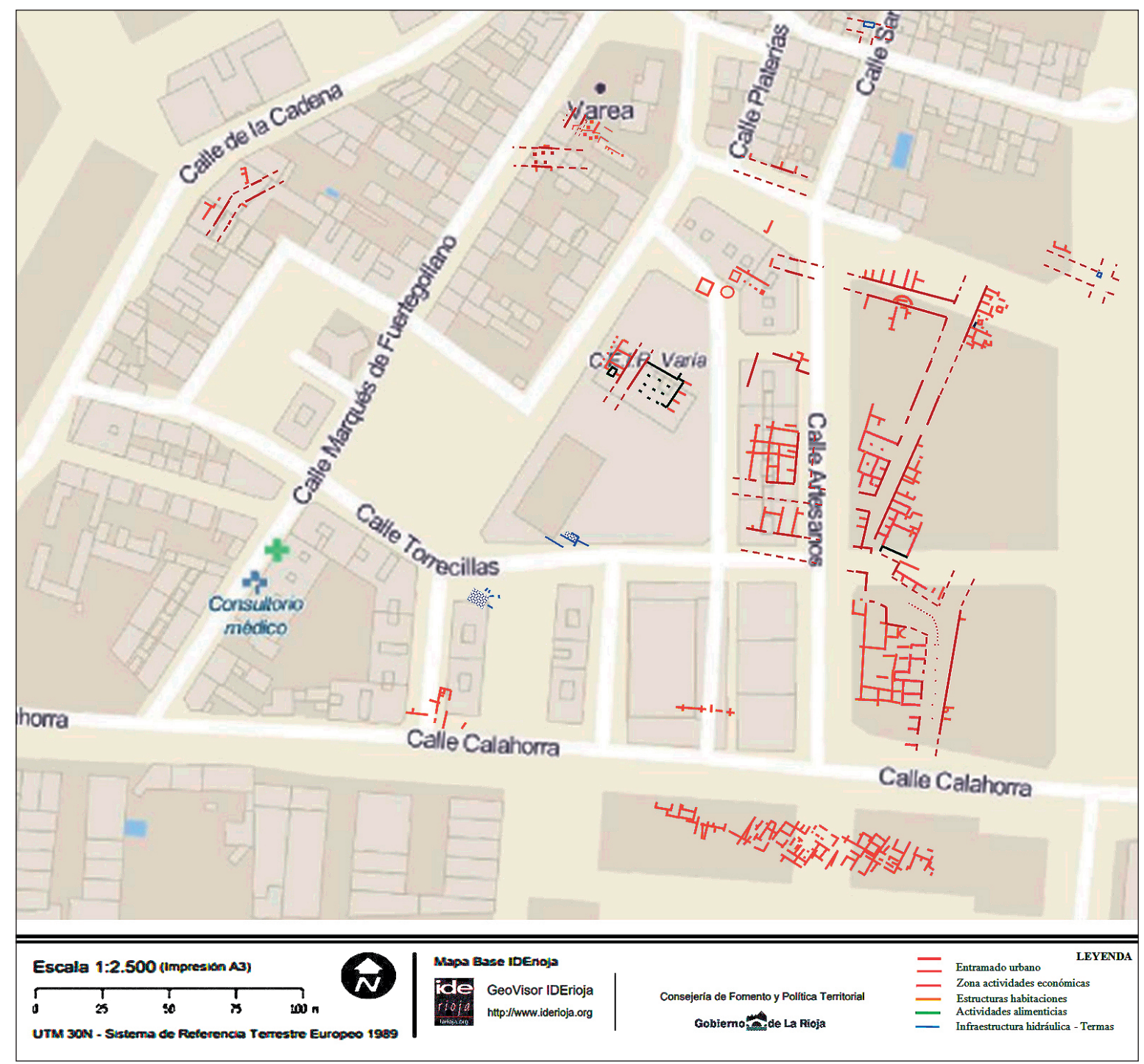

Figura 4

Plano de los restos arqueológicos de Vareia (Varea, Logroño, La Rioja) (Elaboración propia/IdeRioja)

1 Identificación que se basa tanto en su planta comparable a otros horrea con sillares centrales localizados en otras civitates como el que se va a mencionar de Iuliobriga, el de Carmo (Carmona, provincia de Sevilla) (Román, 2001: 237-238 y 240-243), el de la calle Montcada en la antigua Dertosa (Tortosa, provincia de Tarragona) (Diloli et al., 2015: 130-132) o los grandes recintos de almacenaje del portus de Tarraco (Tarragona, provincia de Tarragona) (Adserias et al., 2000: 140-141). 


\subsubsection{Calagurris Iulia (Calahorra, La Rioja)}

Durante el siglo I, se dotó de servicios y se produjo su monumentalización destacando la construcción de un circo, dos complejos termales y un completo sistema de captación, transporte y desagüe del agua (Calonge, 2021: 131-140). Al norte de la ciudad, se desarrolló una zona de trabajo fabril y comercial entre el edificio de espectáculos y las «Termas del Norte». Plenamente integrados en el urbanismo de la ciudad estaban las estructuras productivas encontradas en el solar del centro comercial ARCCA y en la Casa del Oculista.

En el primer caso destacaba la existencia de un edificio diáfano cuya entrada se situaba al norte que debía dar a un decumanus cuyo trazado no se encontró pero que podía ser coincidente con el tramo encontrado en el solar de las calles Dr. Chavarría/ La Concepción, a 80 metros al sureste ${ }^{2}$. En planta presenta muros de opus vittatum separados por elementos verticales que se encontraban alineados y equidistantes con sillares y tambores de columnas que servían como bases para sustentar la techumbre y un pavimento de cemento. En una segunda fase, el interior del conjunto se reforma y los 8 elementos se reducen a 4 sillares apoyados sobre un lecho de cantos rodados (Equipo Calagurris Iulia, 2000: 20-21)3. Durante la fase tardía, el área se convierte en una zona de transformación de materias primas (Iguácel, 2002: 46). En otra parte del solar se constataron otras actividades de transformación y comerciales con un horno, una estructura de combustión de función indeterminada, una pileta de opus caementicium que conservaba una tubería de plomo que le daba servicio y una importante cantidad de fragmentos de cerámica de almacenaje tipo dolium y ánforas de transporte (Equipo Calagurris Iulia, 2000: 20).

En la urbanización de los solares situados al noreste de ARCCA (calle Tilos 1-3/avenida de la Estación 2, Tilos 5, Tilos 7/Chavarría 17) se logró ampliar la información gracias a la constatación de un alto grado de urbanización desde la época del Principado con la existencia de una cloaca que se debía extender bajo una calle (Gil y Luezas, 2012: 360-365). Así mismo, se añadió una nueva industria a las que se tenía constancia: una officina marmorarii (Gil y Luezas, 2011: 111-112), un posible alfar con material cerámica vitrificado o roscos de separación (Gil y Luezas, 2012: 383-383, 394 y 402), restos de escorias de hierro y de industria ósea (Ib.: 383-385 y 395-396). Gracias a la cultura

\footnotetext{
2 Se trata de un pequeño tramo de entre 3 y 4 metros de anchura y 6 de longitud con una orientación noreste-suroeste que separaba dos domi (Tudanca y López de Calle, 2014, 43-44).

${ }^{3}$ Espacios de almacenaje con una planta similar con sillares alineados y equidistantes con respecto a los muros exteriores se han descubierto en la zona portuaria de Oiasso (Irún, Guipúzcoa) (Urteaga Artigas y Alkain Sorondo, 2010: 7-17) o en la Casa de las Fliginae en Hispalis (Sevilla, Andalucía) en un contexto de producción cerámica en el entorno del portus fluvial (Ordoñez Agulla y González, 2011: 168-169).
} 
material, se presupone la existencia de un amplio complejo económico con officinae pero también tabernae y almacenes de carácter comercial con la constatación de consumo de vino tarraconense, salazones béticos o restos de fauna tratada (Ib.: 398-402).

La Casa del Oculista se encuentra a apenas 40 metros al norte del conjunto ARCCA, en los límites del entorno urbano calagurritano. Durante las excavaciones llevadas a cabo a principios de los años 90 se localizaron una serie de estancias distribuidas en tres naves con un acceso enlosado y un vestíbulo empedrado. La cultura material evidenció la existencia de talleres de industria ósea (Tirado, 2005: 137-149), otro de machaque de tejas para la fabricación de mortero y fundiciones metalúrgicas junto a un hipocausto doméstico. A partir del siglo IV se abandonó y se convirtió en una necrópolis (Rodríguez, 1991: 54-55).

\subsubsection{Iuliobriga (Retortillo, Cantabria) y Barcino (Barcelona, Cataluña). Ejemplos a comparar}

La existencia de barrios que combinaban fábricas artesanales con espacios destinados a la vivienda también se encuentra en otras ciudades. Al oeste del foro de Iuliobriga (Retortillo, Cantabria), se trazó un decumanus que articulaba una serie de estancias con una función productiva como un horreum de almacenamiento, una zona de manipulación de la madera, un área metalúrgica y otra de trabajo del cuero lo que indica un alto grado de especialización. Se intuyen también indicios de actividad ganadera (Fernández, 1993: 144-151).

En la Barcino (Barcelona, Cataluña) bajoimperial se ha buscado a su artesanado y se ha observado un dinamismo que supuso la construcción de espacios productivos junto a las domi que los colindaban todo ello integrado en el entramado viario barcinonensis que conserva su uso con múltiples reformas y parcheos. De esta manera, bajo la Plaza de Sant Miquel se encontraron indicios de una almazara, almacenes o zonas comerciales; en el entorno de la Plaza del Rei se añaden industriales textiles (officina fullonica, officina tinctoria...) y una bodega o tabernae de nueva planta junto a la domus de Sant Honorat (Huertas et al., 2017: 247-252).

\subsection{El entorno periurbano}

Los distritos artesanales de la zona periurbana son aquellos que sitúan en el entorno más inmediato de la ciudad y con una conexión directa con esta. Son zonas que se articulan mediante un entramado viario surgido de las necesidades de los talleres. En estos espacios se solían situar las industrias de transformación más profundas y complejas como los centros alfareros o los metalúrgicos. Y para dar salida a los diferentes productos, su localización se hacía coincidir con accesos a calzadas principales que tenían a la ciudad como referencia. 


\subsubsection{Pompaelo (Pamplona, Navarra)}

Uno de los mejores ejemplos se encuentra bajo la Plaza del Castillo en Pamplona (Navarra). Se trataba de un barrio de más $35000 \mathrm{~m}^{2}$ que se localizaba al sureste de la civitas de Pompaelo. Gracias a los datos aportados en diferentes excavaciones llevados a cabo se ha podido dilucidar que el interior de esta zona tenía una ordenación propia con la existencia de calles que articulaban los talleres. Estos poseían suelos enlosados en sus accesos y estaban perfectamente jerarquizados y diferenciados por su producción: alfarería (Figura 5), metalúrgica o manipulado de materiales óseos, entre otras (García-Barberena y Unzu, 2013: 227-237).

Su situación con respecto al resto del urbanismo de la res publica era exógena pese a que la distancia entre el entorno urbano y el barrio artesanal no alcanzaba la decena de metros. Los talleres se ubicaban a las traseras de un amplio complejo termal y se aprovechaban del acceso de agua que la infraestructura pública necesitaba. Así mismo, un antiguo cauce reconvertido en un vertedero también servía de punto de separación entre la ciudad y su suburbio artesanal (García-Barberena y Unzu, 2013: 238-240 y García-Barberena et al., 2015: 413-414).
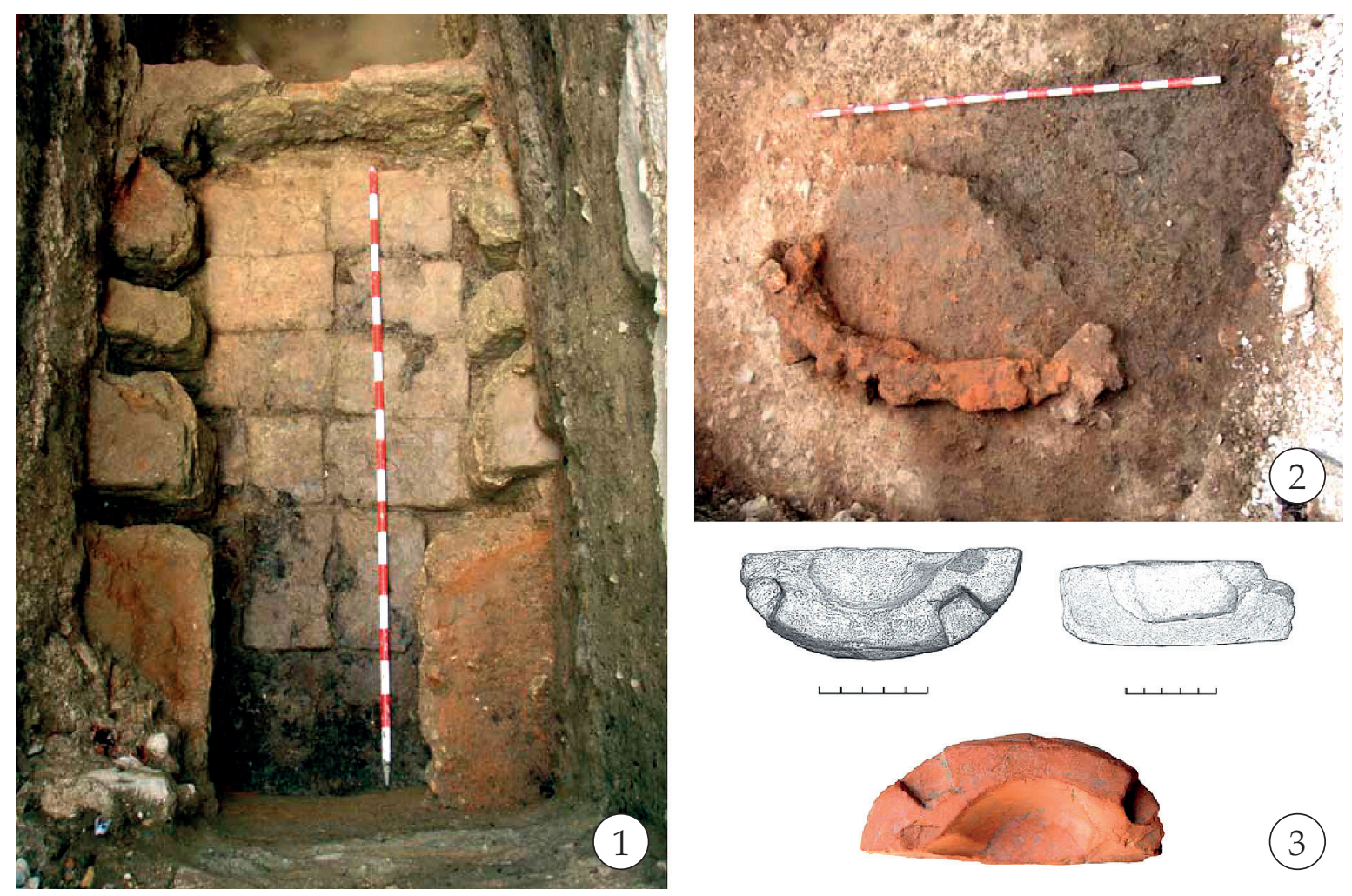

Figura 5

Evidencias de producción alfarera del barrio artesanal de Pompaelo (Pamplona, Navarra): 1. Horno latericio (calle San Agustín), 2. Horno de planta circular (plaza del Castillo) y

3. Fragmento de molde de lucerna modelo Mezq. 50 TSHT

(García-Barberena et al., 2015: 417-418 y 425) 


\subsubsection{Vareia}

Durante el siglo I en Vareia, junto a la calzada bajo la actual calle Calahorra, se desarrolló una serie de industrias que no sobrevivieron al crecimiento de la ciudad, especialmente a finales de esa centuria y principios de la segunda. No se han encontrado los restos de los talleres, que fueron arrasados para dar cabida al nuevo suburbio al sur de la vía, pero sí sus producciones. Se ha podido constatar la existencia de un alfar, relacionado con los talleres tritienses y que fue trasladada ante el avance del entorno urbano; y de una officina lapidaria ligada con la fabricación de epígrafes. Se desconoce cómo era el trazado urbanístico de esta parte de la ciudad, aunque se presupone que se adaptaba al trazado de la arteria de comunicación (Espinosa, 1994: 210-221).

\subsubsection{Calagurris Iulia}

En el norte de Calagurris Iulia (Calahorra, La Rioja) debió existir un suburbio fabril que completaba al distrito artesanal y comercial del entorno del ARCCA. Llama la atención que todo el conjunto mira hacia el septentrión, hacia el trazado de la calzada De Italia in Hispanias (Itin. Ant. 393.1) pero también al Ebro, principal arteria fluvial de la región y donde posiblemente se ubicarían los muelles de la ciudad ${ }^{4}$.

En la parcela del número 5 de avenida de la Estación se exhumaron los restos de un amplio complejo artesanal con dos espacios diferenciados: uno al norte compuesto de un patio abierto y un espacio de manipulado o posible horreum de alimentos ${ }^{5}$; y un taller metalúrgico al sur. Su funcionalidad se pudo establecer gracias a la presencia de restos carbonizados de huesos de aceituna y cereal para el primer caso y de escorias de hierro para el segundo. El almacén tenía unos paramentos de sillarejos, con sillares cúbicos adosados a los muros y otros dispuestos de manera equidistantes en su interior. Estos últimos, además, compartimentados mediante muretes. La estancia fabril contaba con también con paredes ejecutadas de una manera similar y grandes apoyos para los pilares que sustentaban (Angulo y Porres, 2009: 131-134). Ambas continuaban en el solar contiguo y, en el caso de este último, se pudo constatar más sillares de apoyo con la misma orientación a lo que añadía la presencia de fragmentos de mortero hidráulico descontextualizado del que se ignora a qué estructura perteneció (Luezas, 2001: 52-54).

\footnotetext{
${ }^{4}$ En el territorio adscrito a Calagurris Iulia, se ha investigado el alfar de La Maja (Pradejón/Calahorra) donde se ha podido constatar la producción de ánforas de fondo plano símiles a la Oberaden 74 (Luezas, 2017: 180-181) que se podían utilizar para el comercio fluvial, hecho que pudiera apoyar la existencia de un puerto fluvial Este recipiente era uno de los más utilizados para poder abastecer el limes norteño. González constata que este tipo de ánforas es una de las que más llegaron a Germania Inferior con ejemplares en Neuss, Nimega Kops Plateau, Oberaden, Xanten Fürstenberg, Xanten área de la CUT, Haltern, Anreppen oVechten y, gracias al estudio de sus pastas, el origen de la mayoría de ellas estaba en el Ebro (González, 2014: 386-388).

5 Esta última identificación funcional se basa en una comparativa similar a la ya trazada para el posible horreum del solar ARCCA (vid supra nota 3).
} 


\subsubsection{Cartago Nova (Cartagena, Murcia) y Emerita Augusta (Mérida, Extremadura). Ejemplos a comparar}

La existencia de barrios artesanales o de una concentración de estancias productivas en un sector determinado no es algo inusual. Un ejemplo se encuentra en la ladera occidental del Cerro del Molinete de la antigua Cartago Nova (Cartagena, Murcia) donde una amplia excavación puso de manifiesto una reordenación de todo el espacio durante el cambio de Era. Esta supuso la construcción de un cardus a cuyos lados se organizaban las diferentes edificaciones industriales que se alternaban con viviendas en sus plantas superiores. Llegaron a albergar en su interior una tintorería, un conjunto de piletas o estancias de industria alimenticia, así como salas más cuidadas con pavimento de mosaico destinado a exhibir y vender los productos. Tras una serie de reformas y remodelaciones en el siglo II, se produce un abandono a finales de esa centuria y una nueva ocupación a partir de finales del III y en el IV con la introducción de nuevas funciones artesanales como la fabricación de vidrio o la reactivación comercial. El colapso definitivo se produjo a partir del siglo V (De Miquel et al., 2006: 22-39).

Emerita Augusta ha deparado una multitud de estancias productivas como alfares, molinos alimenticios, lavanderías, tintorería, un taller de fabricación de vidrio, hornos metalúrgicos o elementos ligados a la artesanía textil, entre otras. Aunque se han encontrado restos de algunas fullonicae o industrias de producción ósea en el interior de la ciudad, la mayor parte de las zonas fabriles se concentraban en los suburbios del entorno periurbano, especialmente en las cercanías del Guadiana. Entre los talleres, destacan los que se dedicaban a la conservación de las prendas textiles y aquellos que no generaban desperdicios que fueran un obstáculo para la vida de la ciudad (Bustamente, 2013: 131-132).

La mayor parte de la actividad económica, tanto productiva como comercial, se vertebró en el entorno del Anas. El puente sobre el río contaba con un gran tajamar central pentagonal que servía para asegurar la estructura de todo el puente. En esta poderosa infraestructura, existió una estructura comercial ligada a actividades ganaderas: un forum pequarium. Además, se ha especulado con la existencia de un muelle de carga y descarga en las cercanías (Álvarez, 2015: 49-54 y 62-65)

\section{UNA INDUSTRIA DIVERSIFICADA}

\subsection{Alfarería}

De entre los más de $35000 \mathrm{~m}^{2}$ que se estima que ocupa el barrio artesanal de Pompaelo, la zona del manipulado y manufactura del barro es la industria que más cultura material y estructuras ha deparado. Dentro del programa de implementación de nuevas formas de recogida de residuos en la calle San Agustín se encontró un horno de planta rectangular. Estaba ejecutado mediante una combinación de adobes y ladrillos, 
conservaba la cámara de calor, el praefurnium y el corredor que enlaza ambos elementos y una posible producción de material latericio (García-Barberena y Unzu, 2013: 225 para García-Barberana et al., 2015: 416-417). A 100 metros al oeste, junto a la Plaza del Castillo, se halló un segundo horno de tipo vertical, de planta circular y doble cámara todo ello con un diámetro de 2,80 m (García-Barberena y Unzu, 2013: 231).

Como elementos auxiliares se pusieron de manifiesto estructuras ligadas al taller. Una de ellas tenía una planta rectangular de 7,5 $\times 5 \mathrm{~m}$ compartimentada y gracias a la cultura material se ha podido observar una zona habitacional, elementos de uso en el alfar como carretes, separadores o testigos termométricos y producciones de cerámica común, paredes finas, engobadas o lucernas. Superficies enlosadas marcaban los accesos al conjunto alfarero y la necesidad de agua se solucionaba gracias a la existencia de un depósito rectangular (1,40 $\mathrm{m}$ de ancho y 2,10 $\mathrm{m}$ de profundidad), aparejo de sillarejos y un acceso a su interior gracias a unas escaleras (García-Barberena y Unzu, 2013: 227-232). La existencia de moldes ha posibilitado poder establecer una cronología englobada en las tres primeras centurias de nuestra Era y una producción que incluía sigilatas y lucernas (García-Barberana et al., 2015: 415-426).

Junto al canal del acueducto que abastecía a la ciudad y al trazado de la calzada del Ebro se ubicó el primer taller alfarero varayense. Cumplía así la recomendación de que estos centros no estuvieran ubicados en el interior de los enclaves, obtenía un acceso constante al agua y la salida de sus productos gracias a la vía. Se le ha relacionado con las primigenias producciones tritienses, bien por su puesta en marcha por parte de un alfarero o por dependencia directa de los centros del Najerilla. No se han localizado estructuras del taller ya que fue arrasado ante el crecimiento de la ciudad en el siglo II, pero sí parte de sus vertederos con fragmentos de moldes, elementos utilizados en las labores de manipulado y restos de sus manufacturas. Gracias a la cultura material se sabe que produjo formas decoradas que beben directamente de los estándares tritienses que se sirve de frisos y metopas para organizar motivos geométricos, vegetales o zoomórficos. Las piezas que dotan de personalidad al centro son un conjunto de 6 vasos de terra sigillata decorados a molde con improntas monetales de época antonina (Antonino Pío, Marco Aurelio y Lucio Vero) y de joyas (Espinosa, 1994: 210-217 y Sáenz y Sáenz, 2013: 471).

Estas producciones enlazan este primigenio centro con su heredero que se trasladó a lo largo del siglo II a un $1 \mathrm{~km}$ al sur, al actual Polígono de la Portalada, debido a la expansión urbanística de la ciudad. Se han conservado restos de un horno con una cámara de combustión de planta rectangular, diversos muros, moldes, piezas pasadas de cocción y tortas de barro procedentes del descarte o el sobrante de material fechadas entre la tercera y cuarta centuria. Mantuvo la decoración con improntas monetales, en este caso, Lucio Vero y también ejecutó cerámica engobada, común, material latericio y sigillata lisa y decorada con motivos vegetales y figurativos mediante el uso de un punzón (Espinosa et al., 1994: 344-346 y Sáenz y Sáenz, 2013: 473). 
Se han encontrado indicios de actividad alfarera en Andelos gracias a la presencia de cerámica vitrificada (Mezquíriz, 2009a: 74) y Calagurris Iulia ${ }^{6}$ que suma a las piezas pasadas de cocción y roscos en el entorno del solar ARCCA, zona artesana del norte (Gil y Luezas, 2011: 109 y 2012: 382-383, 394 y 402), indicios de un taller bajo la actual Glorieta de Quintiliano. Este fue amortizado con la construcción del circo y formaba parte del suburbio occidental de la primigenia ciudad Julio-Claudia. No se han encontrado estructuras de la zona manufacturera pero sí abundante cultura material que incluye separadores, ajustadores, un tubo de aireación o fragmentos de molde junto a las piezas producidas: dolia, material latericio, cerámica de paredes finas, común y engobada (Cinca et al., 2009, 178-195).

\subsection{Metalurgia}

La presencia de espacios para la manipulación de metales, especialmente de hierro, bronce y plomo, ha sido constatada tanto en los barrios artesanales plenamente integrados como en los distritos periféricos. De entre los primeros destaca la fragua bajoimperial de Vareia que recoge una tradición ya localizada en el suburbio sur de época antonina. Se trata de una estancia de planta rectangular, diáfana y con un pavimento de cantos rodados y manteado de tierra con un amplio pórtico hacia el cardus (Figura 6). La zona de trabajo se encontraba al norte con las huellas de la estructura de combustión y el yunque de forjado junto con abundantes escorias. Su producción era eminentemente local y orientado especialmente al arreglo del utillaje agrícola y herramientas de otras actividades artesanales o el ámbito doméstico. Al norte, se han encontrado pruebas del trabajo de un broncista que utilizaba como materia prima chatarra o la reutilización de piezas desgastadas. Comparte con el herrero el destino de su manufactura y su ámbito de producción (Espinosa, 1994: 339-342).

La zona de explotación metalúrgica del barrio artesanal de Pompaelo se localiza en el área suroccidental. No se han encontrado los hornos o las zonas de forjado, pero sí abundantes escorias que han permitido averiguar que las elaboraciones eran de hierro y bronce. Se fabricaban herramientas y útiles, pero también se trataban los materiales para su traslado en forma de lingotes. Una cubeta $(6,5 \times 4 \times 1,20 \mathrm{~m})$ excavada en la roca con un fondo acondicionado con un empedrado de canto rodado proporcionaba el agua suficiente para en mantenimiento de la actividad mientras que estructuras de habitación evidencia el urbanismo del lugar y una posible zona comercial (GarcíaBarberena y Unzu Urmeneta, 2013: 234-236).

\footnotetext{
${ }^{6}$ José Luis Cinca Martínez ha escrito una recopilación de las evidencias de producción alfarera de la civitas calagurritana, especialmente las suburbanas, que vienen a confirmar la diversidad económica de la que disfrutó este enclave urbano (Cinca, 2021:117-140).
} 


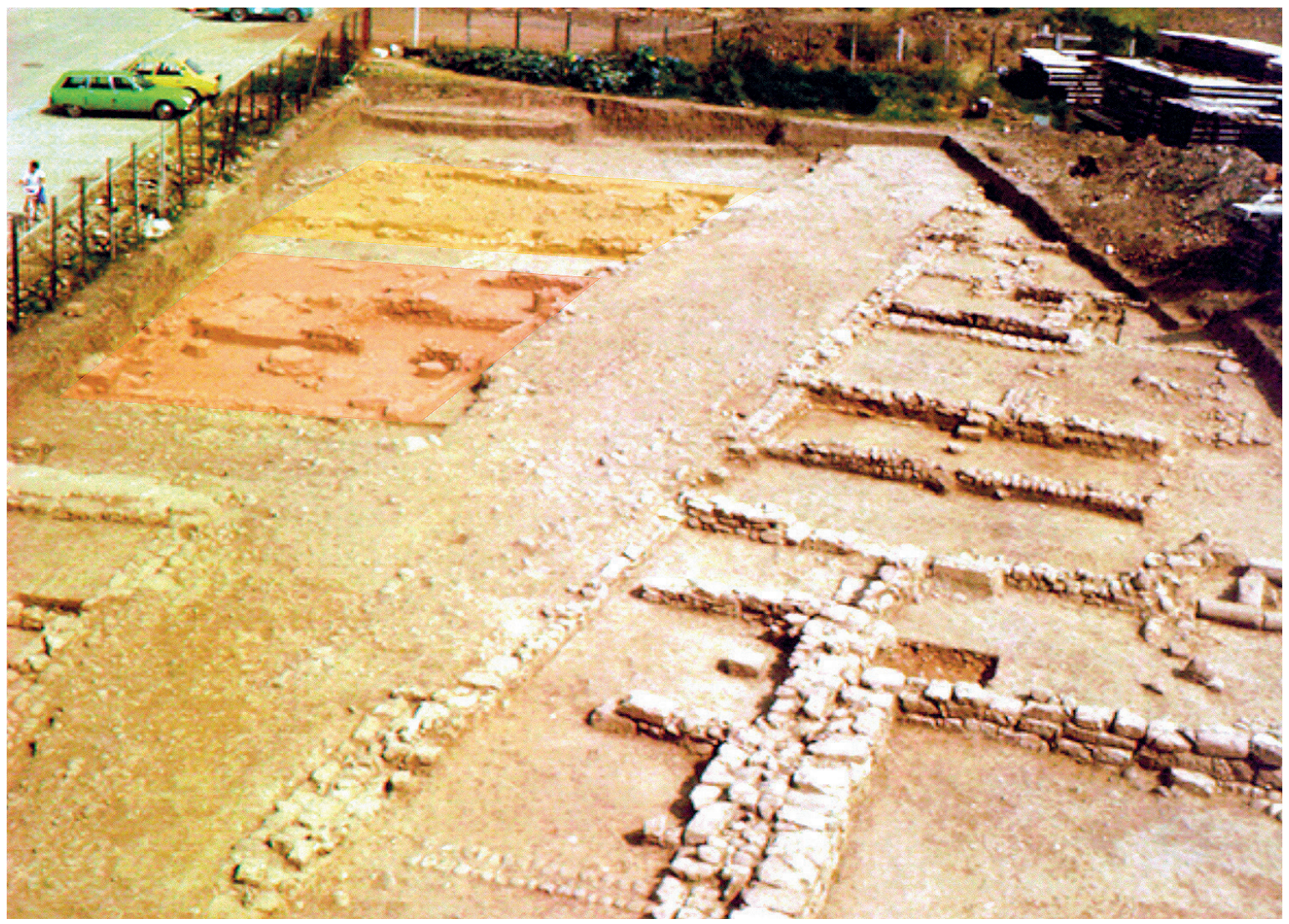

Figura 6

Fragua (tono amarillento) y taberna textrina (tono anaranjado) de Vareia (Archivo municipal de Logroño)

Santa Criz de Eslava también ha deparado la existencia de crisoles y de escorias de hierro y bronce que evidencian la existencia de una industria metalúrgica en este civitas. Parte de la materia prima podría proceder de los alrededores del enclave urbano, pero sí es interesante el número de objetos férricos como llaves, espátulas, campanitas, elementos de mobiliario, armas o instrumentos quirúrgicos (Andreu Pintado et al., 2019: 90-93).

En Calahorra también se desarrolló una actividad de manipulado del metal tal y como demuestran las escorias encontradas en las inmediaciones del Centro Comercial ARCCA (Gil, 2012: 384 y 396) o la Casa del Oculista (Rodríguez, 1991: 55). Sin embargo, la única estructura se localiza en el suburbio norte en avenida de la Estación 5. El conjunto situado al sur de este amplio complejo está parciamente excavado y consta de paramentos de sillares y sillarejos y puntos centrales para el sostenimiento de los pilares de la techumbre. El último uso de la zona como vertedero dificulta encontrar las zonas funcionales destinadas a la metalurgia, aunque dentro de la cultura material se han encontrado una gran cantidad de residuos ferrosos, así como pequeños elementos de hierro, pero insuficiente para discernir las partes del mismo como puede ser las estructuras de combustión, la fragua o el entorno comercial (Angulo y Castillo, 2009: 133-134). 


\subsection{El tratamiento de los alimentos}

Las industrias de transformación de los productos del sector primario con destino al consumo humano estaban plenamente integradas en la vida económica de las ciudades. Se localizan tanto en su interior como en su suburbio periurbano y tienen la peculiaridad de formar una simbiosis con las cosechas y las producciones realizadas en los enclaves rurales como pueden ser las villas de su entorno más inmediato (Calonge, 2020: 254-284).

En el barrio artesanal de Andelos, cerca del decumanus 2, se han encontrado evidencias de trabajo de despiece de animales sin poder determinar su ubicación exacta (Mezquíriz, 2009a: 74). En Vareia únicamente el periodo bajoimperial ha deparado estancias destinadas tanto al tratamiento y almacenamiento de alimentos. En la zona manufacturera se ha podido localizar un molino junto a la plaza que formaba la intersección entre el cardus porticado el decumanus. In situ se ubicaba una plataforma de tegulae y sillarejo donde se asentaban las piezas destinadas a la molienda de las que se hallaron la plataforma de 1,50 m de diámetro, $18 \mathrm{~cm}$ de grosor y un agujero central de 10,5 cm así como una meta muy desgastada. El molino debía ser de tracción humana ya que la superficie de la habitación no era lo suficientemente grande como para poder tener un animal que accionase la maquinaria. Una posible cuadra para la guarda de animales de transporte se encontraba en la estancia contigua al este con indicios de heno en descomposición (Espinosa et al., 1994: 342.343).

Bajo el actual colegio «Varia», se conservan los restos de un lagar identificado como parte de una planta de elaboración de aceite excavado en el suelo y una estructura de almacenaje. Esta estancia de carácter privado tiene planta rectangular, acceso desde del oeste, fuertes muros perimetrales de sillarejos y cantos rodados y 9 apoyos centrales ordenadas de tres en fondo que servían como base sustentante de los pilares de la techumbre y la posibilidad de ser la base de un sistema de suelo elevado. Se le ha atribuido la función de guarda de grano por su modo de ejecución y por el elevado número de molinos hallados (Espinosa et al., 1994: 329-332).

Dos horrea más se han podido investigar en Calahorra. Uno se localiza en la zona oriental del solar ARCCA y se han conservado tres muros, uno de ellos con tres paramente unidos por elementos verticales que están perfectamente alineados con 8 apoyos centrales equidistantes y alineados que soportarían la estructura del tabulalatum. Tenía un pavimento inferior de argamasa y sufrió una profunda reforma durante la segunda centuria donde se pasan de 8 a 4 grandes basas centrales que se asientan sobre un preparado de sillarejo (Figura 7). Este almacén se integraba en un complejo de mayor tamaño que aunaba actividades de comercio y artesanado (Equipo Calagurris Iulia, 2000: 20-21 e Iguacel, 2003: 46). 


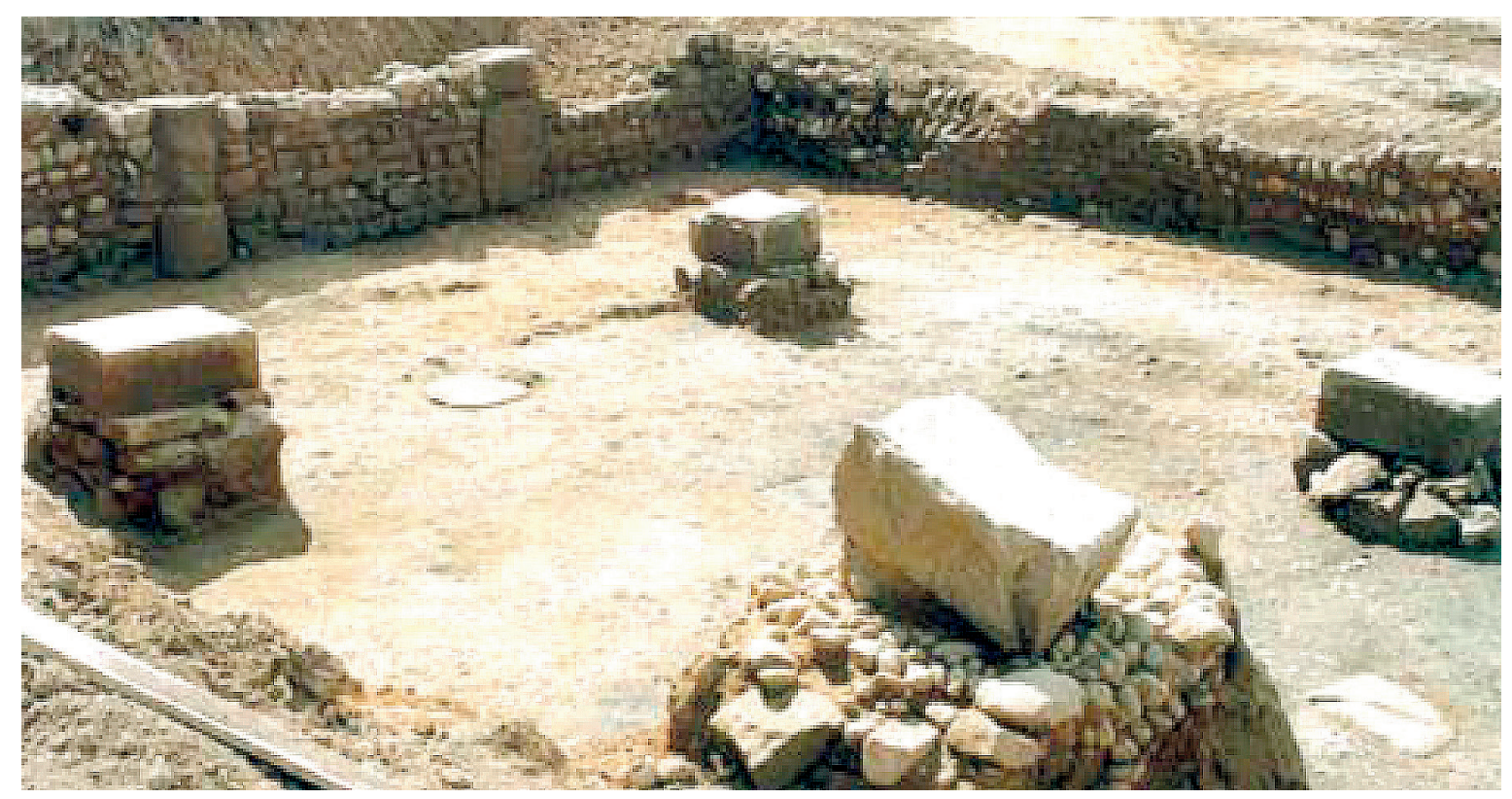

Figura 7

Interior del horreum del solar ARCCA. Fase II

(Foto de A. Pérez/Asociación de Amigos de la Historia de Calahorra) (Castillo, 2011: 112)

Abierto a un amplio patio dentro del conjunto note de avenida de la Estación 5, se desarrolló una industria de almacenaje y transformación alimenticia. En una primera fase, se construyó un taller de manipulado de alimentos que usaba un espacio de combustión mientras que en una segunda fase se transforma en un posible horreum. Este tiene una superficie excavada de 13,5 m de longitud y $9 \mathrm{~m}$ de anchura. Contaba con amplios muros perimetrales realizados con sillares y sillarejos. Tenía grandes piedras cúbicas adosadas a los paramentos y otros dispuestos de manera equidistante en el interior con muretes compartimentados en su interior. Se desconoce si estos servían como espacios diferenciados de almacenaje o como base de un suelo elevado (Angulo y Porres, 2009: 131-133).

En Gracurris (Alfaro, La Rioja) se han hallado indicio de actividad oleícola fechado en el cambio de Era. Los restos se circunscriben a un lagar de planta irregular de 2,70 m de longitud máxima, $2 \mathrm{~m}$ de anchura y una profundidad conservada de 1,20 m. Estaba realizado con un encofrado de material hidrofugante y una base de cantos rodados, sillarejo y yesos. Al este se encontraron dos grandes manchas de 1,64 m de diámetro y que correspondería con las bases de la prensa (Hernández y González, 1983: 612-613). A esto se le sumaba un potente estrato de $20 \mathrm{~cm}$ de potencia y varios metros cuadrados de superficie de restos óseos y escamas de pescado que pudiera ser el vertedero de un complejo industrial ligado a estos animales, pero sin poder especificar ni las estructuras ni su ubicación dentro de la ciudad (Martínez, 1993: 25). 


\subsection{Industria textil}

Dentro del barrio artesanal de Andelos, al oeste del cardus porticado se descubrió una estancia con dos cubetas gemelas ejecutas con argamasa que se relacionaban con dos dolia de pequeño tamaño que habían sido empotradas en el pavimento. La instalación se completaba con un canal proveniente del ramal sur del acueducto, sumideros y un desagüe que vertía al entramado viario. Se interpretó como una officina lanificaria o una officina infectoria dedicado al tratamiento, limpieza y acabado de las telas (Mezquíriz, 2009a: 74).

La presencia de bolas de azul egipcio en la cultura material del distrito manufacturero de la Plaza del Castillo de Pamplona ha posibilitado poder establecer que durante el siglo II estuvo funcionando una fullonica aunque no se ha determinado dónde se situaba la instalación o si se trataba de una lavandería o de una tintorería (GarcíaBarberena y Unzu, 2013: 237).

En la Vareia bajoimperial, en una esquina formada por el cardus principal y un decumanus que partía de este, se encontró en 1988 una taberna textrina de $50 \mathrm{~m}^{2}$. Un almacén ocupaba el ángulo noreste mientras que el resto del frente septentrional debió ser la zona del telar donde se conservaba una plataforma elevada de tegulae que sirvió para recoger el tejido ya confeccionado. Al oeste se ejecutó, mediante unas hiladas de piedras, un depósito o espacio protegido que conservaba un conjunto de 28 pondera en su interior (Espinosa et al., 1994: 346-347) (Figura 4). En la ampliación sur de la ciudad del siglo II también se hallaron evidencias de talleres textiles (Tudanca y López de Calle, 2018: 51-54).

\subsection{Otras}

El conjunto de industrias que funcionaban, tanto en los barrios artesanales integradas en el urbanismo de la ciudad como en los suburbios periurbanos, era más diverso que los ya mencionados. Algunos de estos talleres debían compartir espacios e infraestructuras para poder optimizar los recursos. Un ejemplo se encuentra nuevamente en la Plaza del Castillo de Pamplona donde se ha rastreado una importante actividad alfarera pero también restos de actividad de vidrieros con la presencia de lingotes, escorias, vidrios estirados o crisoles. Ambos gremios se beneficiaron de estructuras comunes como podían ser las de combustión o las ligadas con el almacenamiento y tratamiento del agua (García-Barberena y Urmeneta, 2013: 237).

La presencia de industria ósea no es algo inusual ya que era un material muy trabajado para fabricar útiles como agujas, herramientas o elementos de adorno personal. En Calagurris Iulia se han encontrado indicios de esta actividad con abundante materia prima procedente de cápridos, porcinos o équidos. En el solar ARCCA (Gil y Luezas, 2012: 383-385 y 395) o en la Casa del Oculista (Rodríguez, 1991: 55 y Tirado, 2005: 137-149) se han identificado agujas, pasadores, cucharillas, styla de escritura, placas 
decorativas, enmangues para armas o alfileres para el cabello tanto en proceso de talla como ya finalizados. Sin embargo, sólo se ha logrado identificar un lugar de manufactura en la antigua ubicación de la Fábrica Torres, al norte de la ciudad, en un poyo usado como banco de trabajo junto al que se hallaron 213 fragmentos en 8 sondeos llevados a cabo en el solar7. La producción de este taller o conjunto de talleres en diferentes puntos de la ciudad debió ser abundante durante el siglo I. A modo de ejemplo, durante la investigación del tramo de cloaca de la calle San Andrés 17-29, el $22 \%$ de la cultura material correspondía a útiles óseos en proceso de fabricación o ya terminados (Cinca, 1991: 146-147).

Cuantitativamente similar es un amplio repertorio de 34 objetos ejecutados en hueso encontrados en un espacio privado de la ciudad de Los Bañales (Uncastillo, provincia de Zaragoza). Se trata de una taberna que daba al entramado viario donde se han encontrado indicios de almacenaje en grandes tinajas, posible manipulación de elementos metálicos y una acumulación de materia prima ósea, especialmente bóvidos. Se trataría de un espacio productivo englobado en un entorno eminentemente multifuncional (Andreu, 2013: 128-133).

En Pompaelo también hubo un importante volumen de trabajo sobre huesos. En la Plaza del Castillo se descubrió un vertedero de $30 \mathrm{~m}^{2}$ con descartes, agujas, lanzadores o punzones y también la zona de trabajo. Esta contaba con un pavimento realizado con cantos rodados y argamasa y de diferentes herramientas entre las que se han conservado tres yunques, espátulas o elementos punzantes (García-Barberena y Urmeneta, 2013: 233-134). Materia prima en diferente grado de ejecución procedente de la actividad de un taller especializado en esta industria también se encontraron en Andelos (Mezquíriz Irujo, 2009b: 194-195) y en Santa Criz de Eslava (Andreu Pintado et al., 2019: 76-80).

Los útiles óseos ${ }^{8}$ o de metal formaban parte de los instrumentos usados por los curtidores, cuyo rastro es más complicado de seguir debido a que su materia prima es orgánica y, por ende, finita. Sin embargo, si se han podido tener indicios en el suburbio sur vareyense en época Antonina (Tudanca y López de Calle, 2018: 51-55) y en los seguimientos arqueológicos del solar Aquavox de Pamplona, el sector más oriental del barrio artesanal. De esta manera, gracias a unas especiales condiciones de humedad, se lograron exhumar recortes de cuero procedentes de un taller que muy posiblemente se dedicase a la reparación de calzado (García-Barberena y Unzu, 2013: 223-224).

7 El poyo de trabajo se ejecutó con un murete de lajas de arenisca. Entre los fragmentos aparecieron 5 agujas de coser, 10 alfileres de cabello, 7 punzones, 23 fustes de agujas o alfileres, 20 esbozos de varillas, 3 astas, 2 epífisis de équido, 119 de herbívoro y 24 de fragmentos serrados (Tirado, 1998: 198-200 y 2000: 13-16).

8 Para una aproximación a la diversidad de objetos óseos encontrados en Navarra ver Tabar y Unzu, 1985: 187-226 y Mezquíriz, 2009b: 161-198. 
El trabajo de la piedra es otra de las actividades que se desarrollaban en las civitates del Ebro Medio y se puede constatar gracias a la cultura material. Cara ha proporcionado elementos suntuarios pétreos como basas, fustes, pedestales o dos capiteles de orden corintio con la parte posterior tallada en forma cuadrangular para ser colocadas. Un tercer capitel se encontró en proceso de talla donde ya se habían empezado a moldearse las volutas y las coronas de acanto (Mezquíriz, 2006: 177-178 y 180).

Otras piezas en similar estado han conducido a ubicar un taller de cantería de piedra arenisca al sur de Vareia. En este caso se trata de varias lajas de piedra y tres fragmentos de estelas destinadas a ser epígrafes. De estas últimas, dos tienen un cuerpo rectangular coronada con un frontón triangular, uno con la superficie para ser inscrita ya preparada y en la otra le faltaba la parte superior. La tercera varía porque el coronamiento era semicircular con un acabado fino y le faltaba colocar la placa para estar finalizada (Espinosa, 1994: 217-221). Este tipo de producción tiene similitudes con dos epígrafes funerarios encontrados en Alberite y Recajo, ambas con cuerpo rectangular y cabecera semicircular con decoración vegetal (Espinosa, 1986: 32-33 y 37-38) e influencia formal en el denominado como «Conjunto del Camero Nuevo», especialmente en las piezas con coronación en forma de frontón triangular y en la ordenación de los registros decorativos (Espinosa, 1989: 403-416 y 1994: 219-220).

Las producciones de los talleres de cantería de Cara y Vareia utilizaron como materia prima la piedra arenisca, una de las más abundantes en el valle del Ebro. En el entorno del solar ARRCA en Calahorra, la cultura material deparó la presencia de seis fragmentos de mármol sin pulir que debían ser procesados en la ciudad en una officina marmorarii y que habría llegado usando los diferentes medios de comunicación terrestre o fluvial (Gil y Luezas, 2011: 111-112).

\section{CRONOLOGÍA: MANTENIMIENTO Y TRANSFORMACIÓN}

El barrio artesanal vareyense ha deparado únicamente contextos bajoimperiales fechados entre finales del siglo III ${ }^{9} \mathrm{~V}$ pero que se desarrolló sobre un urbanismo ejecutado durante las dos primeras centurias. La zona sur del cardus estaba porticada y en el periodo tardío se pretende mantener. La mayor parte de las tabernae también perduraron en su actividad, aunque se observa una invasión de la antigua zona pública lo que obligó a tener que abrir un establecimiento comercial para que se mantuviera la circulación. Las actividades económicas de tratamiento e intercambio se mantuvieron adaptadas a cada periodo (Espinosa et al., 1994: 339-348)

\footnotetext{
9 La cultura material fechada en el siglo III corresponde a la zona norte del barrio artesanal donde se han encontrado indicios de actividad metalúrgica broncista (Espinosa et al., 1994, 339-341).
} 
Se trata de una evolución cronológica similar al trazado para la zona de «La Morería» en la ladera occidental del Cerro del Molinete en Cartagena. Tras el abandono de esta zona artesanal a finales del siglo II, se produce una reocupación y recuperación de las manufacturas con nuevas industrias, espacios habitaciones con hogares y entornos comerciales con sustitución de suelos, nuevas estructuras y presencia de los primeros enterramientos. El colapso de todo este entorno fue progresivo entre finales de la cuarta centuria y a lo largo de la quinta (Egea et al., 2006: 56-58).

Varea creció gracias a su situación privilegiada que dominaba una amplia vega agrícola formaba por los cursos bajos del Iregua y del Leza y a la actividad comercial ligada al puerto y su ubicación en la calzada del Ebro. La ciudad superó el trazado de la vía, que discurría al sur por la actual calle Calahorra, y la integró dentro del conjunto urbano gracias a la construcción de un nuevo suburbio con una urbanización que seguía el entramado del resto de la civitas en época antonina (Tudanca y López de Calle, 2018: 51-58). En esas mismas fechas, algunas de las industrias más contaminantes se desplazaron más al sur como es el caso de los alfares (Espinosa, 1994: 210-217 y Espinosa et al., 1994: 344-346). Actividades económicas y zonas de vivienda se dieron la mano durante más de un siglo hasta que en el siglo III comienza su declive y abandono.

Coincidente con esta última cronología se produjo la reorganización del barrio artesanal y de otras partes del interior de la ciudad. Uno de los ejemplos más significativos se encuentra bajo el colegio Varia puesto que los espacios de habitación con decoración monumental se construyeron junto a espacios productivos en un modelo que recuerda a las villae. Especialmente interesante es el caso del horreum que formaba parte de un conjunto mayor junto con una domus con grandes mosaicos (Espinosa et al., 1994: 329-331).

Las zonas artesanales de Calagurris Iulia tienen su inicio de producción durante el cambio de Era con la figlina de la rotonda del Quintiliano que fue completamente amortizada por la construcción del circo. Sin embargo, será durante el siglo I cuando se establezcan de forma estable en el norte de la ciudad, junto al trazado de la vía. Durante esta primera centuria ya estaban en funcionamiento los conjuntos industriales encontrados en la Casa del Oculista (Rodríguez, 1991: 55) y en ARCCA (Equipo Calagurris Iulia, 2000: 20-21). Al igual que en el Vareia, la época antonina marca para la actual Calahorra una expansión económica y urbanística. Junto a las reformas en las Termas del Norte (Calonge, 2021: 139-140), también se produce una reordenación del espacio de almacenaje del solar ARCCA y se fundan nuevas actividades de nueva planta mirando al norte como las halladas en avenida de la Estación lo que supone una ampliación del urbanismo de la ciudad (Angulo y Porres, 2009: 156-157). 
Entre finales del siglo III y principios del IV, Calahorra se amuralla y continúa siendo una importante civitas. El espacio extramuros se reorganizó con el circo convertido en una gran cantera y un retroceso en los sectores artesanales. La Casa del Oculista y avenida de la Estación cambiaron de función para ser una necrópolis, un patrón que se encuentra en gran parte del sector norte de la ciudad (Rodríguez, 1991: 55 y Angulo y Porres, 2009: 157). ARCCA, sin embargo, se reconvirtió con nuevas industrias (Equipo Calagurris Iulia, 2000: 21 e Iguacel, 2002: 46).

El barrio artesanal de la Plaza del Castillo en Pompaelo empezó a funcionar durante la primera centuria en una zona que combinaba espacios productivos, comerciales y de habitación. Gracias a la cultura material se ha podido establecer que su plenitud estuvo situada en el siglo II, coincidente con la máxima expansión urbanística de Vareia, la ampliación de industrias en Calagurris Iulia y la ejecución de un segundo ramal del acueducto de Andelos para dar servicio a la zona productiva de la ciudad (Mezquíriz y Unzu, 1988: 245-250 y Mezquíriz, 2009a: 137-139). Durante el siglo III y IV, el distrito artesanal pamplonense decae y se abandona de manera paulatina coincidiendo con el amurallamiento de la ciudad, aunque la producción alfarera sí sobrevive (García-Barberena y Unzu, 2013: 221 y García-Barberana et al., 2015: 427).

\section{CONCLUSIONES}

En el urbanismo y en el entorno periurbano más cercano de las ciudades romanas del Ebro Medio se han podido constatar la existencia de actividades artesanales y fabriles plenamente integradas y planificadas. Vareia y Andelos han demostrado cómo los recintos productivos se ubicaban en el interior de los entornos urbanos y cómo se dotaban de los servicios necesarios para su funcionamiento, destacando el segundo ramal del acueducto en el caso navarro.

Varea y la antigua Calagurris Iulia también muestran la disparidad de espacios fabriles que se desarrollaron en ellas. Destaca en este punto la vinculación de estos centros con la calzada del Ebro. El conjunto de complejos calagurritanos se situó mirando hacia el norte ${ }^{10}$, lugar donde discurría la vía mientras que en los vareyenses ocurre lo mismo, pero en el sur llegando incluso a integrar la infraestructura viaria. Esta carretera posibilitaba que los productos pudieran salir hacia la rica zona del Noroeste, la capital conventual de Caesaraugusta y la zona del Levante. Además, ambas ciudades eran nudos de comunicaciones: Vareia aprovechaba el curso del Iregua para buscar el valle del Duero usando el paso de Piqueras mientras que en la margen izquierda del

\footnotetext{
${ }^{10}$ Las diferentes referencias a la calzada del Ebro en el entorno calagurritano se distribuyen por la zona norte de la ciudad siguiendo la terraza más elevada para evitar inundaciones (Cinca, 1990: 98-101).
} 
Ebro partía otra que cruzaba Navarra de oeste a este teniendo una parada en Andelos, cerca de su barrio artesanal. Calahorra se servía del Cidacos vía el puerto de Oncala para llegar al Alto Duero y conectaba con el valle del Arga al norte para poder acceder a Pompaelo y, desde allí, Oiasso (Irún, Guipúzcoa).

Por otro lado, hay una clara vocación en la producción de los distritos artesanales analizados. Aquellos que se integran dentro de las ciudades se orientan hacia un consumo más local. Así mismo, destaca el hecho de que las industrias más contaminantes, como pueden ser los alfares, suelen situarse en la periferia junto a complejos más grandes que buscan generar elaboraciones que buscan mercados a nivel regional. Estos últimos suelen tener ámbitos de separación física con el resto del entorno urbano como pueden ser los vertederos de Pamplona, que diferencia el barrio artesanal del complejo termal de la Plaza del Castillo, y de Calahorra, que distingue la zona fabril del solar ARCCA del entorno del circo en el actual Paseo del Mercadal (Figura 8).

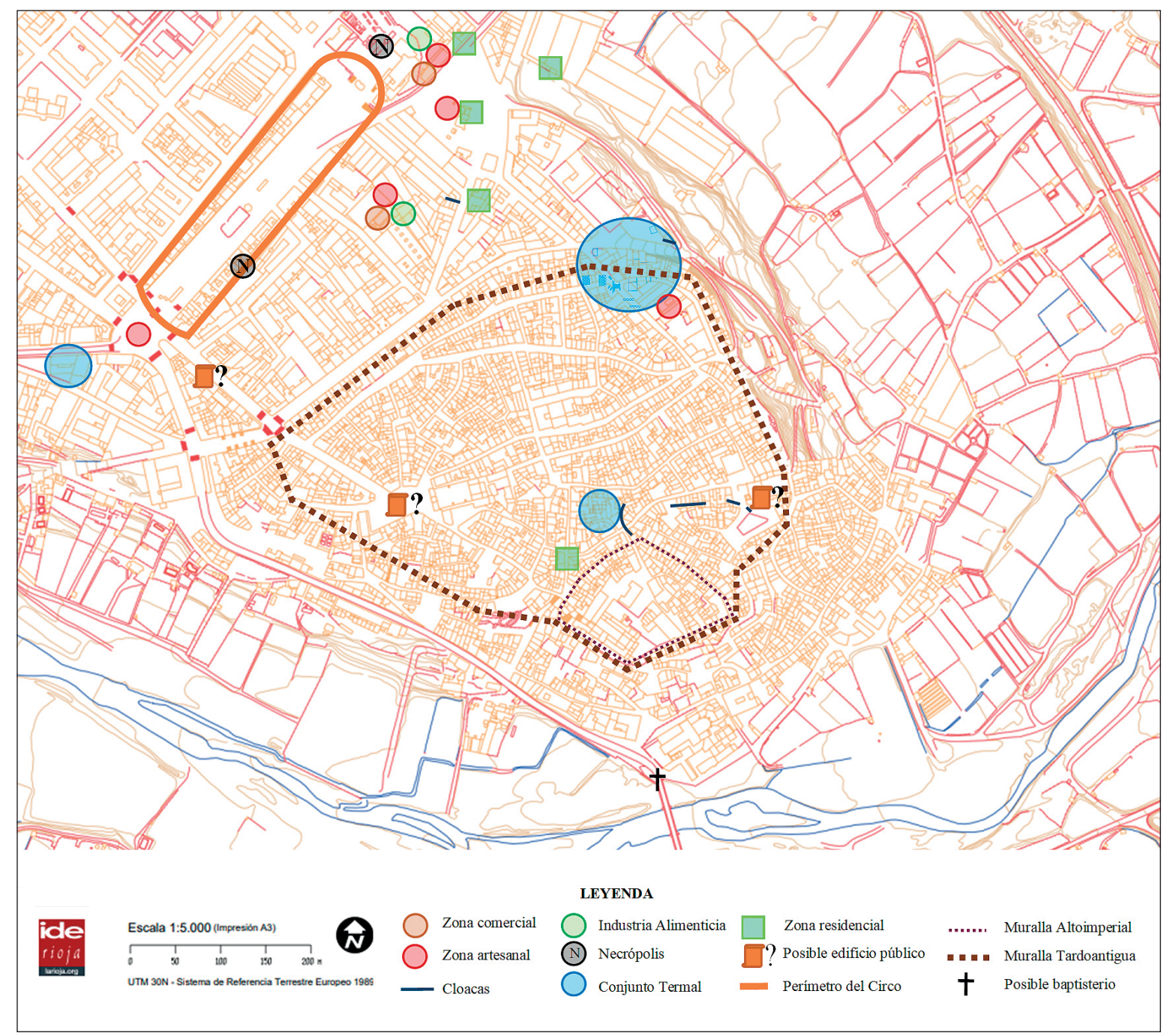

Figura 8

Plano de situación de los recintos excavados en Calahorra (Elaboración propia) 
Urbanísticamente, las áreas periurbanas están jerarquizadas y diferenciadas por industrias. Este hecho se observa muy claramente de nuevo en Pamplona y Calahorra donde se distribuyen cada una de las zonas manufactureras en torno a estructuras comunes como pueden ser pozos de acceso al agua. Así mismo, disponían de corredores interiores de tránsito a modo de calles. Y estos dos casos no son aislados ya que se pueden observar también en el conjunto del Cerro del Molinete en Cartago Nova o en la zona oeste de Iuliobriga.

Y aunque aún queda por establecer la funcionalidad y ubicación definitiva de algunas industrias como puede ser la officina marmorarii de Calagurris Iulia, los talleres de cantería de Vareia y Cara o la planta de procesamiento de pescado en Graccurris, sí se establece la multitud de actividades que se llevaban a cabo: metalúrgicas de bronce, plomo y hierro; almacenamiento y tratamiento de alimentos, industria textil incluyendo curtidores, alfarería, el trabajo óseo y sobre el vidrio así como el comercio de todas ellas en los mismos establecimientos o en tabernae del entorno más inmediato.

Cronológicamente, se observa un comienzo de estas industrias en el siglo I de nuestra Era manteniéndose a lo largo del tiempo hasta la quinta centuria teniendo su cénit en siglo II durante el cetro de los Antonino y los primeros Severos. En los casos de los conjuntos artesanales que se integran dentro de las ciudades, la acción económica continúa a lo largo del tiempo en el mismo espacio, aunque la tipología puede ser diferente y difieren de las zonas periurbanas que pasan de ser muy dinámicas a no tener actividad o a ser esta muy residual. Unas áreas que recordaban a su pasado industrial y comercial, pero se adaptaban a los nuevos cambios dentro de sus entornos urbanos.

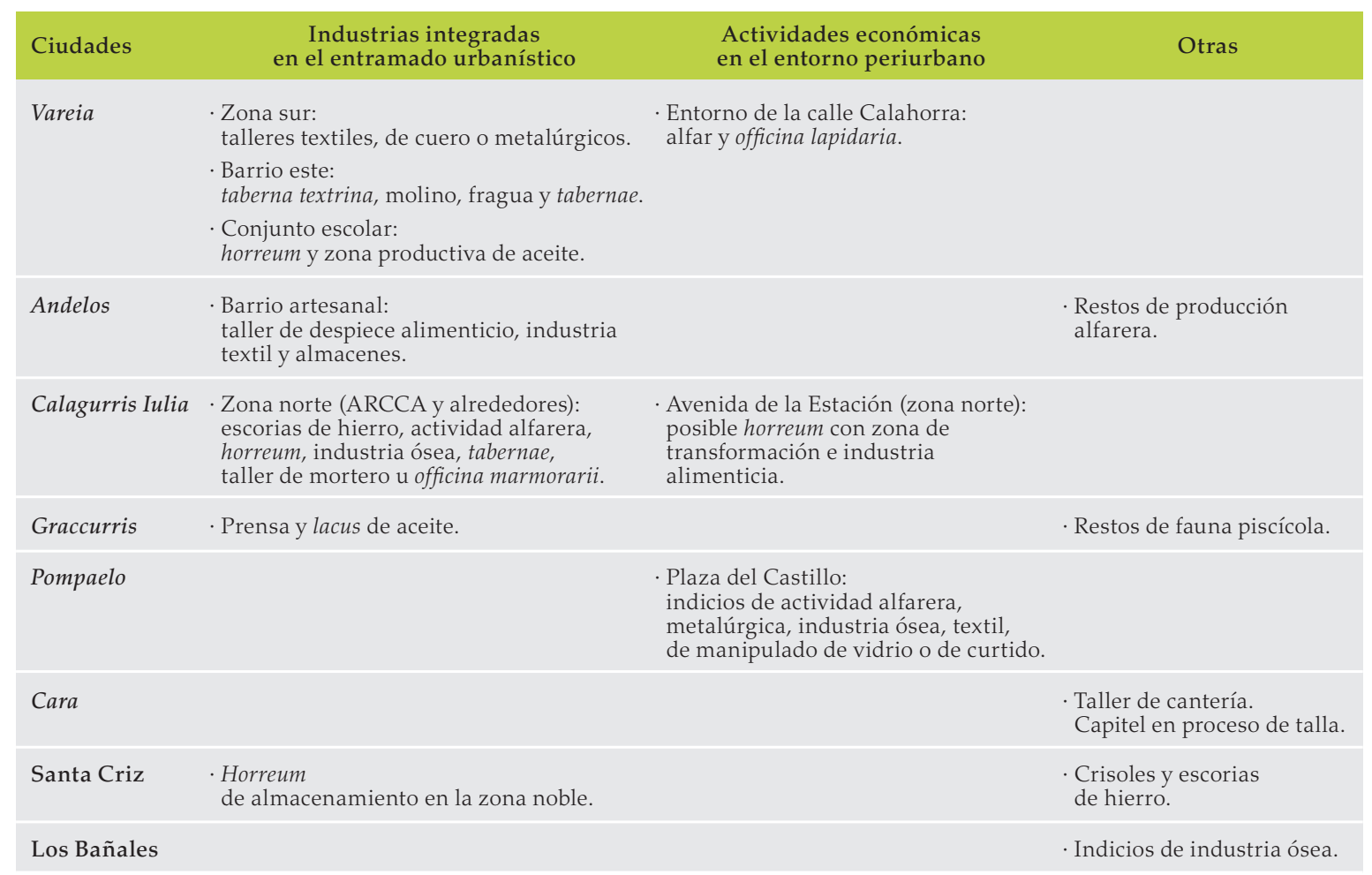

Figura 9

Cuadro-resumen de las industrias constatadas en ciudades del Ebro Medio 


\section{REFERENCIAS BIBLIOGRÁFICAS}

ADSERIAS SANS, M., POCIÑA LÓPEZ, C. A. y REMOLÁ VALLVERDÚ, J. A. (2000): «L'habitat suburbá portuari al sector afectat pel PERI 2 (Jaume I 1-Tabacalera)» en RUIZ DE ARBULO BAYONA, J. (ed): Tàrraco 99. Arqueología d'una capital provincial romana, Universitat Rovira iVirgili, 137-154, Tarragona.

ÁLVAREZ MARTÍNEZ, J. M. (2015): «El tajamar del Puente romano de Mérida y la navegabilidad del Ana», Revista de Estudios Extremeños, n. 71.1, 37-66, Badajoz.

ANDREU PINTADO, J. (2013): «Sobre un repertorio de objetos de hueso romanos del norte de la Tarraconense: Los Bañales de Uncastillo (Zaragoza, España», Habis, n. 44, 115139, Sevilla.

ANDREU PINTADO, J., DELAGE GONZÁLEZ, I. y ROMERO NOVELLA, L. (2019): Santa Criz de Eslava. Reflejos de Roma en territorio vascón, Departamento de Cultura, Deporte y Juventud del Gobierno de Navarra, Pamplona.

ANGULO SÁENZ, T. y PORRES CASTILLO, F. (2009): «Intervención arqueológica realizada en el solar sito en avenida de la Estación 5 de Calahorra», Kalakorikos, n. 14, 127-158, Calahorra.

ARMENDÁRIZ AZNAR, R. M. y SÁEZ DE ALBÉNIZ ARREGUI, M. P. (2016): «Aproximación al paisaje urbano del yacimiento arqueológico de Santa Criz (Eslava)», Trabajos de arqueología navarra, n. 28, 245-285, Pamplona.

BUSTAMANTE ÁLVAREZ, M. (2013): «El trabajo artesanal en Augusta Emerita durante los siglos I-IV d. C.», Zephyrus, n. 72, 113-138, Salamanca.

CALONGE MIRANDA, A. (2021): «Calagurris Iulia. Ciudad y territorio en los procesos de monumentalización de época altoimperial», Cuadernos de arqueología de la Universidad de Navarra, n. 29, 129-156, Pamplona.

CASTILLO PASCUAL, M. J. (2011): «La red catastral» en CASTILLO PASCUAL, M. J., ESPINOSA RUIZ, U., CINCA MARTÍNEZ, J. L., LUEZAS PASCUAL, R. A., GÓMEZ SEGURA, E. y BARENAS ALONSO, R. (coords.): «Edad Antigua» en CINCA MARTÍNEZ, J. L. y GONZÁLEZ SOTA, R. (coord.): Historia de Calahorra, Asociación de Amigos de la Historia de Calahorra, 108-115, Pamplona.

CEBRIÁN FERNÁNDEZ, R., ANDREU PINTADO, J., ROMERO NOVELLA, L., MATEO PÉREZ, R. y DELAGE GONZÁLEZ, I. (2020): «Arquitectura pública de Santa Criz de Eslava (Navarra, Conventus Caesaraugustanus) en época altoimperial», SPAL, n. . 29.1, 213-242, Sevilla.

CEPEDA OCAMPO, J. J. e IGLESIAS GIL, J. M. (2015): «Iuliobriga. Intervenciones arqueológicas recientes (2001-2017)», Sautuola, n. 20, 169-183, Santander.

CINCA MARTÍNEZ, J. L. (1990): «Tramo de calzada romana en el valle medio del Ebro (Calahorra, La Rioja)» en Simposio sobre la red viaria en la Hispania romana, Diputación de Zaragoza e Institución Fernando el Católico, 95-112, Zaragoza.

CINCA MARTÍNEZ, J. L. (1991): «Un nuevo hallazgo arqueológico de Calahorra» en Amigos de la Historia de Calahorra (coord.), Arqueología de Calahorra. Miscelánea, Asociación de Amigos de la Historia de Calahorra, 205-236, Calahorra. 
CINCA MARTÍNEZ, J. L. (2021): «Alfares suburbanos en Calagurris Iulia (Calahorra, La Rioja). Síntesis a veinte años de información», Kalakorikos, n. 26, 117-140, Calahorra.

CINCA MARTÍNEZ, J. L., IGUÁCEL DE LA CRUZ, P. y ANTOÑANZAS SUBERO, M. A. (2009): «El alfar de "Calagurris" (Calahorra, La Rioja)», Kalakorikos, n.. 14, 173-212, Calahorra.

DILOLI FONS, J., FERRÉ ANGUIX, R., JARREGA DOMÍNGUEZ, R. y VILÁ LLORACH, J. (2015): «La ciudad de Dertosa durante el altoimperio. La ocupación suburbial del Barranco del Rastre», Zephyrus, n.. 76, 121-139, Salamanca.

EJEA VIVANCOS, A., DE MIQUEL SANTED, L. E., MARTÍNEZ SÁNCHEZ, M. A. y HERNÁNDEZ ORTEGA, R. (2006): «Evolución urbana de la zona "Morería". Ladera occidental del Cerro del Molinete (Cartagena)», Mastia: revista del Museo Arqueológico Municipal de Cartagena, n. 5, 11-59, Cartagena.

ESPINOSA RUIZ, U. (1986), Epigrafía romana de La Rioja, Instituto de Estudios Riojanos, Logroño.

ESPINOSA RUIZ, U. (1989), «Una officina lapidaria en la comarca del Camero nuevo (La Rioja)», Gerión. Estudios sobre la Antigüedad en Homenaje al profesor Santiago Montero Díaz, n. extra 2, 403-416, Madrid.

ESPINOSA RUIZ, U. (1994): «Actividades económicas» en Espinosa Ruiz, U. (coord.): «Antigüedad» en Sesma Muñoz, J. A. (coord.): Historia de la ciudad de Logroño, Ibercaja y Ayuntamiento de Logroño, 179-224, Logroño.

ESPINOSA RUIZ, U., ABASCAL PALAZÓN, J. M., TIRADO MARTÍNEZ, J. A. y MARTÍNEZ MINA, I. (1994): «Actividades económicas» en ESPINOSA RUIZ, U. (coord.): «Antigüedad» en SESMA MUNOZZ, J. A. (coord.): Historia de la ciudad de Logroño, Ibercaja y Ayuntamiento de Logroño, 329-338, Logroño.

ESPINOSA RUIZ, U., MARTÍNEZ CLEMENTE, J., VICENTE BRAVO, L. C. y CASTILLO PASCUAL, M.J. (1994): «Actividades artesanales» en ESPINOSA RUIZ, U. (coord.): «Antigüedad» en SESMA MUÑOZ, J. A. (coord.): Historia de la ciudad de Logroño, Ibercaja y Ayuntamiento de Logroño, 339-348, Logroño.

EQUIPO CALAGURRIS IULIA (2000): «El proyecto Calagurris Iulia: actuaciones efectuadas durante el año 2000», Estrato. Revista riojana de arqueología, n. 12, 14-22, Logroño.

FERNÁNDEZ VEGA, P. A. (1993): Arquitectura y urbanística en la ciudad romana de Juliobriga, Servicio de publicaciones de la Universidad de Cantabria y Ayuntamiento de Torrelavega, Santander.

GARCÍA-BARBERENA UNZU, M. y UNZU URMENETA, M. (2013): «Un barrio artesanal en la ciudad romana de Pompelo», Cuadernos de arqueología de la Universidad de Navarra, n. 21, 219-255, Pamplona.

GARCÍA-BARBERANA UNZU, M., MEZQUÍRIZ IRUJO, M. A. A. y UNZU URMENETA, M. (2015): «El centro alfarero de Pompelo: piezas singulares y fabricación de lucernas» en AGUILERA ARAGÓN, I., BELTRÁN LLORIS, F., DUEÑAS JIMÉNEZ, M. J., LOMBA SERRANO, C. y PAZ PERALTA, J. A. (coord.): De las ánforas al museo: estudios dedicados a Miguel Beltrán Lloris, Institución Fernando el Católico, 413-427, Zaragoza. 
GIL ZUBILLAGA, L. y LUEZAS PASCUAL, R. A. (2011): «Intervenciones arqueológicas en varios solares del Centro Comercial ARCCA de Calahorra (I)», Kalakorikos, n. 16, 85114, Calahorra.

GIL ZUBILLAGA, L. y LUEZAS PASCUAL, R. A. (2012): «Intervenciones arqueológicas en varios solares del Centro Comercial ARCCA de Calahorra (II)», Kalakorikos, n. 17, 355 406, Calahorra.

GONZÁLEZ CESTEROS, H. (2014): Ánforas hispanas en la Germania Inferior antes de la formación de la provincia (20 a. C.-69 d. C.), Universitat Rovira iVirgili, Berlín/Tarragona.

HERNÁNDEZVERA, J. A. y GONZÁLEZ BLANCO, A. (1983): «Más restos de industria oleica romana en La Rioja» en BLÁZQUEZ MARTÍNEZ, J. M. y REMESAL RODRÍGUEZ, J. (coord.): Producción y comercio del aceite en la Antigüedad: segundo congreso internacional (Sevilla, 24-28 de febrero de 1982), Universidad Complutense, 611-616, Madrid.

HUERTAS ARROYO, J., PEÑA CERVANTES, Y. y MIRO ALAIX, C. (2017): «La panadería de la calle Avinyó y el artesanado tardorromano en la ciudad de Barcino (Barcelona)», SPAL, n. 26 , 237-258, Sevilla.

IGUÁCEL DE LA CRUZ, P. (2002): «La ciudad romana. El trazado urbano» en IGUÁCEL DE LA CRUZ, P., PAVÍA LAGUNA, E., CINCA MARTÍNEZ, J. L. y CASTILLO PASCUAL, M. J. (coord.): Así era la vida en una ciudad romana: Calagurris Iulia, Asociación de Amigos de la Historia de Calahorra, 39-50, Calahorra.

LUEZAS PASCUAL, R. A. (2001): «Calahorra. Sondeos arqueológicos en el solar de la avenida de la Estación n. 7», Estrato, n. 13, 52-54, Logroño.

LUEZAS PASCUAL, R. A. (2017): «Producción, consumo e iconografía del vino en Calagurris y su entorno», Kalakorikos, n. 22, 173-199, Calahorra.

MARTÍNEZ CLEMENTE, J. y GALLEGO PUEBLA, R. (1994): «Vareia. La ciudad bajoimperial» en ESPINOSA RUIZ, U. (coord.) «Antigüedad» en SESMA MUÑEZ, J. A. (coord. gen.), Historia de la Ciudad de Logroño, Ayuntamiento de Logroño e Ibercaja, 315-328, Logroño.

MARTÍNEZ TORRECILLA, J. M. (1993): «Excavaciones arqueológicas en las Eras de la Cárcel. Alfaro», Estrato. Revista riojana de Arqueología, n. 5, 23-26, Logroño.

MEZQUÍRIZ IRUJO, M. A. (1996): «Claves del urbanismo romano en el territorio de Navarra» en QUEROL FERNÁNDEZ, M. a A. y CHAPA BRUNET, M. T. (coord.): Complutum. Homenaje al profesor Manuel Fernández-Miranda, n. 6 Extra 1, 441-450, Madrid.

MEZQUÍRIZ IRUJO, M. A. (2006): «La antigua ciudad de los carenses», Trabajos de arqueología navarra, n. 19, 147-267, Pamplona.

MEZQUÍRIZ IRUJO, Ma A. (2009a): Andelo. Ciudad romana, Institución Príncipe de Viana y Gobierno de Navarra, Pamplona.

MEZQUÍRIZ IRUJO, M. A. A. (2009b): «Producción artesanal romana: objetos de hueso encontrados en yacimientos navarros», Trabajos de arqueología navarra, n. 21, 161-198, Pamplona.

MEZQUÍRIZ IRUJO, M. A. y UNZU URMENETA, M. (1988): «De hidráulica romana. El abastecimiento de agua a la ciudad romana de Andelos», Trabajos de arqueología navarra, n. 7, 237-266, Pamplona. 
ORDOÑEZ AGULLA, S. y GONZÁLEZ ACUÑA, S. (2011): «Horrea y almacenes en Hispalis. Evidencias arqueológicas y evolución de la actividad portuaria» en ARCE MARTÍNEZ, J. y. GOFFAUX, B. (coord.): Horrea d'Hispania et de la Méditerranée Romaine, Casa de Velázquez, 159-184, Madrid.

RODRÍGUEZ MARTÍNEZ, P. (1991): «Excavación de urgencia en el solar conocido como "La Casa del Oculista" (Calahorra)», Estrato. Revista riojana de arqueología, n. 3, 54-55, Logroño.

ROMÁN RODRÍGUEZ, J. M. (2001): «El almacenamiento de grano de Carmona: el horreum de San Blas» en CABALlOS RUFINO, A. (ed.): Carmona Romana, Ayuntamiento de Carmona y Universidad de Sevilla, 233-250, Sevilla/Carmona.

SÁENZ PRECIADO, J. C. y SÁENZ PRECIADO, M. P. (2013), «Figlinae romanas de Vareia y Calagurris» en BERNAL CASASOLA, D., JUAN TOVAR, L. C., BUSTAMANTE ÁLVAREZ, M., DÍAZ RODRÍGUEZ, J. J. y SÁEZ ROMERO, A. M. (eds.), Hornos, talleres y focos de producción alfarera en Hispania. Actas del I Congreso Internacional de la SECAH, Universidad de Cádiz y SECAH, 469-478, Cádiz/Madrid.

TABAR SARRÍAS, M. I. y UNZU URMENETA, M. (1985): «Agujas y punzones de hueso de época romana en Navarra», Trabajos de arqueología navarra, n. 4, 187-226, Pamplona.

TIRADO MARTÍNEZ, J. A. (1998): «Restos de industria ósea en el solar de la antigua Fábrica Torres», Kalakorikos, n. 3, 197-206, Calahorra.

TIRADO MARTÍNEZ, J. A. (2000): El yacimiento del Solar Torres: niveles de ocupación prerromanos y romanos. Excavaciones arqueológicas en Calahorra, Asociación de Amigos de la Historia de Calahorra, Calahorra.

TIRADO MARTÍNEZ, J. A. (2005): «Objetos de hueso del solar de la Casa del Oculista. Calle Chavarría. Calahorra (La Rioja)», Kalakorikos, n. 10, 137-149, Calahorra.

TUDANCA CASERO, J. M. y LÓPEZ DE CALLE CÁMARA, C. (2014), Al encuentro de Dionisos. La muerte dulce de Calagurris Iulia Nassica, Museo de la Rioja y Gobierno de La Rioja, Logroño.

TUDANCA CASERO, J. M. y LÓPEZ DE CALLE CÁMARA, C. (2018): «Al otro lado del espejo. Vareia 465 A. D.» en TEJADO SEBASTIÁN, J. M. (coord.): Vislumbrando la tardoantigüedad. Una mirada desde la arqueología, Instituto de Estudios Riojanos, 41-69, Logroño.

URTEAGA ARTGAS, M. y ALKAIN SORONDO, P. (2010): «L'horreum de Oiasso», Colloque International. Entrepôts et systèmes de skockages dans le monde greco-romain Antique. Etat de lieux, Mars 2010, Aix-en-Provence. 